\title{
KESENIAN NANDUNG DI MASYARAKAT MELAYU KOTA RENGAT KABUPATEN INDRAGIRI HULU PROVINSI RIAU (KAJIAN SEMIOTIKA)
}

\author{
Rofiandri Suardi \\ Program Pascasarjana, Universitas Negeri Semarang \\ E-mail: acordioner@ymail.com
}

\begin{abstract}
Abstrak
Nandung adalah salah satu sastra lisan yang ada di Kota Rengat, Kabupaten Indragiri Hulu Provinsi Riau. Nandung dilantunkan oleh ibu-ibu yang ingin menidurkan anaknya di dalam buaian. Isi syair nandung adalah tentang pengajaran agama, kasih sayang orang tua, pengajaran dan pendidikan, akhlak mulia, dan nasehat-nasehat. Pengkajian makna dalam syair nandung ini menggunakan teori semiotika, yakni memahami tanda dari sintaksis, semantik dan pragmatik. Hasil kajian dari syair nandung ini adalah pertama tentang sintaksis, yaitu tentang teks, terdapat 4 baris kalimat pada 1 bait yang serupa dengan pantun, dengan bait yang tersusun dari sampiran dan isi, dengan berpola $\mathrm{a} b$ dan a b. Kedua, tentang semantik, membahas tentang arti kata/bahasa, bahwa syair nandung memiliki arti tentang petuah agama, kasih sayang orang tua, akhlak mulia, pengajaran dan pendidikan, serta nasehat. Konsep ketiga yaitu pragmatik, membahas tentang makna dari hubungan antara teks dan arti kata/bahasa, bahwa yang diharapkan dari syair nandung ini adalah agar kelak anak-anak menjadi orang yang patuh kepada agama, orang tua, serta menjalani kehidupan dengan akhlak yang mulia. Makna yang terdapat dalam syair nandung ini adalah dalam menjalani kehidupan harus berpegang teguh pada agama, selalu melakukan kebaikan, mengingat jasa-jasa orang tua yang telah mendidik dan membesarkan anaknya, dan melakukan segala perintah Allah SWT dan menjauhi segala larangan-Nya.
\end{abstract}

Kata kunci: nandung, makna, semiotika Aart Van Zoest.

\section{A SEMIOTIC STUDY ON NANDUNG ART IN MELAYU COMUNITY IN RENGAT CITY, INDRAGIRI HULU DISTRICT, RIAU PROVINCE}

\begin{abstract}
Nandung is one of the existing oral literatures in Rengat City, Indragiri Hulu Regency of Riau Province. Nandung is sung by mothers who want to put their children sleeping in the cradle. The contents of this poem are about the teaching of religion, parental love, teaching and educating, noble character, and advice. To study the meaning of this poem is by using the semiotics theory of Aart Van Zoest, about understanding of syntactical, semantic and pragmatic signs. The first result of the analysis of this poem is about syntax, which is about the text, there are 4 lines of sentences in a stanza similar to the pantun, with stanzas composed of sampiran (introduction) and contents, patterned $\mathrm{a} b$ and $\mathrm{a} b$. The second concept is semantics, discusses about the meaning of the word / language, that poem has a meaning about religious advice, parental affection, noble character, teaching and education, and advice. The third concept is pragmatic, discusses about the meaning contained from the relationship between text and the meaning of words / language, that is expected from this poem is children could become obedient to religion, to parents, and live a life with a morally noble. The meaning contained in this poem is living a life must stickle to religion, always do good, considering the love of parents who have educated and reared their children, and do all the commands of Allah and stay away from all his prohibitions.
\end{abstract}

Keywords: nandung, meaning, semiotics, Aart Van Zoest. 


\section{PENDAHULUAN}

Kota Rengat adalah salah satu kota yang berada di Kabupaten Indragiri Hulu Provinsi Riau. Dahulu, di kabupaten ini berdiri sebuah kerajaan yang bernama Kerajaan Indragiri. Replika bangunan kerajaan masih berdiri di sekitar kawasan wisata Danau Raja, yang terletak di tengah Kota Rengat. Keberadaan bekas kerajaan ini juga bisa dibuktikan dengan adanya kompleks pemakaman para raja yang pernah memerintah di Kerajaan Indragiri. Salah satu makam yang ada di kompleks ini adalah makam Raja Narasinga II. Sebelum dipimpin oleh Raja Narasinga II, kerajaan ini dipimpin oleh Raja Indragiri I yang dikenal dengan nama Raja Kecik Mambang dengan gelar Raja Merlang. Kerajaan Indragiri memiliki hubungan yang erat dengan Kerajaan Melaka, karena pada zaman dahulu wilayah Indragiri merupakan daerah kekuasaan dari Raja Melaka. Bisa diperkirakan, karena adanya kaitan inilah mayoritas masyarakat di Kota Rengat Kabupaten Indragiri Hulu adalah suku Melayu dan beragama Islam, sama dengan masyarakat di Kerajaan Melaka.

Kota Rengat mayoritas terdiri atas suku Melayu, akan tetapi selain suku Melayu, terdapat juga suku-suku lainnya yang berada di Kota Rengat dan Kabupaten Indragiri Hulu ini, yaitu suku Minang, Batak, Jawa, Tiong Hoa, Banjar, Sunda, dan juga suku pedalaman seperti Sakai dan Talang Mamak. Dengan beragamnya suku yang ada, maka terdapat juga beragam kebudayaan dan kesenian yang berkembang di Kota Rengat.

Masyarakat Melayu Riau khususnya Kota Rengat dan Kabupaten Indragiri Hulu, memiliki beragam jenis kesenian, seperti Surat Kapal, Berdah, Berzanji, Begambus, Dabus, Besilat, Begawai, Tari Rentak Bulian dan Nandung. Bagian dari beragam kesenian yang ada, nandung merupakan salah satu kesenian yang masih dilestarikan di Kabupaten Indragiri Hulu khususnya di daerah seberang Kota Rengat, seperti Kampung Pulau, Kampung Besar Seberang, dan Rantau Mapesai.

Nandung adalah sastra lisan yang digunakan untuk menidurkan anak yang disampaikan dengan syair yang berbentuk pantun, dan dilantunkan dengan berirama (bersenandung). Syair dalam nandung seperti pantun yang memiliki sampiran dan isi, serta dengan bentuk pola $a b$ dan $a b$. Nandung juga memiliki arti yang sama dengan kata nyanyian, yaitu melantunkan lirik-lirik (pantun) dengan cara dinyanyikan dengan menggunakan irama yang khas untuk menidurkan anak. Nandung berisikan syair tentang agama, nasehat, akhlak, tunjuk ajar, dan pengajaran pendidikan.

Istilah nandung yang dimaksud dalam hubungannya dengan salah satu genre sastra lisan masyarakat Indragiri Hulu dapat didefinisikan sebagai berikut: rangkaian kata berbentuk pantun yang dinyanyikan dengan irama untuk mendodoi atau menidurkan anak di kalangan masyarakat tempatan dan atau yang berasal dari Indragiri Hulu. (Darmawi, 2006: 17).

Masuknya kesenian nandung ini, tidak diketahui pasti kapan asal muasalnya dan tahun berapa mulai ada dalam masyarakat melayu Kota Rengat Indragiri Hulu, karena pada zaman dulu, ibu-ibu sudah terbiasa menandungkan anaknya ketika di dalam buaian. Ketika bapakbapak sedang mencari nafkah seperti berkebun, mencari ikan di sungai, dan berdagang di pasar, ibu-ibu di rumah akan menandungkan anaknya menjelang tidur, dan ketika anak sudah tidur, maka ibu bisa menjalankan aktivitasaktivitasnya di rumah (Wawancara Mailiswin, 23 Februari 2017).

Awalnya, nandung hanya berupa nyanyian atau lantunan kalimat La Ilaha Illalah dan ditambahkan dengan kalimat-kalimat yang mampu membuat anak tidur dalam buaian. Perkembangannya, nandung menjadi lebih kompleks dengan ditambahkannya pantun yang berisikan tentang agama, nasehat, akhlak dan pendidikan. Seiring waktu berlalu, masyarakat mulai menambahkan cara melantunkan nandung sama dengan irama saat membacakan ayat suci Al-Qur'an, sehingga pembacaan syair nandung ini memiliki ciri khas dan terus diwariskan secara turun temurun di dalam keluarga masyarakat daerah Kota Rengat dan sekitarnya. Syair nandung yang dibacakan oleh seseorang yang paham seni membaca 
Al-Qur'an, akan terasa berbeda dengan orang pada umumnya, karena irama yang dilantunkan akan memiliki perbedaan dari segi durasi, pola ritme dan melodi syairnya. Dilihat dari perkembangannya, saat ini kesenian nandung mulai ramai diperlombakan dan dipertunjukan dalam acara-acara besar daerah Kota Rengat Kabupaten Indragiri Hulu.

Berdasarkan penjelasan yang telah diuraikan, bisa dikatakan bahwa kesenian nandung ini erat kaitannya dengan syair atau lirik yang memiliki makna. Untuk mengetahui dan memahami tentang makna apa yang terdapat dalam lantunan-lantunan kesenian nandung ini, maka akan dikaitkan dengan teori semiotika. Teori semiotika bisa dikatakan sebagai teori yang membahas tentang tanda dan penandaan. Sistem penandaan seperti bahasa, dalam teori semiotika, dipahami sebagai tanda-tanda yang membentuk makna.

Teks secara keseluruhan merupakan tanda dengan semua cirinya bagi pembaca, teks sastra ini mengantikan sesuatu yang lain yakni, kenyataan yang dipanggil yang secara kasar dapat ditunjuk dalam penulisannya, ciri-ciri penyajian dalam teks-teks adalah suatu tanda yang dibangun dari tanda-tanda yang lain yang lebih rendah yang memiliki sifat kebahasaan (Zoest, 1993:61).

Aart Van Zoest (dalam Rusmana, 2014: 33) mengatakan bahwa berkenaan dengan masalah tanda-tanda dalam bahasa, Charles Morris, membagi tiga klasifikasi semiotika sebagai berikut, (1) Semiotika sintaksis (studi relasi formal tanda-tanda), yaitu studi tentang tanda yang berpusat pada penggolongan, hubungan antar tanda, proses kerja sama dalam menjalankan fungsinya, (2) Semiotik semantik (studi relasi dengan penafsirannya) yaitu studi tentang tanda yang menonjolkan hubungan tanda-tanda dengan acuannya dan interprestasi yang dihasilkannya, dan (3) Semiotika pragmatik, yaitu studi tanda yang mementingkan hubungan antar tanda dengan pengirim dan penerimanya.

\section{PEMBAHASAN}

Harus diakui bahwa semiotika termasuk salah satu pendekatan yang diminati oleh berbagai ahli seni saat ini, yaitu teater, film, desain, lukis, musik, tari dsb. Sementara itu, di dunia sastra semiotika telah lama diminati dan berkembang dalam berbagai variannya masingmasing. Secara etimologis, kata semiotika berasal dari kata Yunani semeion yang berarti tanda (Sudjiman dalam Sudjiman \& Zoest, 1992:vii). Tanda itu sendiri sebenarnya membentang di sekitar kehidupan ini seperti pada gerak isyarat, lampu lalu lintas, sesaji dalam upacara ritual, upacara pernikahan dll, dalam hal ini, struktur yang membangun sebuah karya teater, sastra, film, tari, musik dll., itupun dapat disebut sebagai semiotika. (Sahid, 2016: 1).

Semiotika adalah teori atau ilmu tentang tanda dan penandaan. Ahli semiotika, semisal, Rolland Barthes dalam pemikiran awalnya melihat kehidupan sosial dan kultural dalam bingkai kerangka tanda, dan dari sini dalam bingkai kerangka beberapa sifat objek yang tidak bersifat esensial. Hal tersebut seperti dituliskan oleh Jean Baudrillard dalam bukunya, The System of Object. Melalui pendekatan semiotika yang didasarkan atas kerangka linguistik Saussurean, kehidupan sosial menjadi arena pertarungan demi prestise dan status sosial; atau dapat juga menjadi tanda pertarungan ini. Semiotika juga mengkaji bagaimana tanda melakukan penandaan, seperti dalam naskah sastra konvensional dan beberapa dokumen hukum, atau dalam iklan dan perilaku ragawi. (Sunarto, 2016: v).

Semiotika muncul pada abad ke-19 dan awal abad ke-20. Semiotik bertujuan untuk mengetahui makna-makna yang terkandung dalam sebuah tanda atau menafsirkan makna tersebut sehingga diketahui bagaimana komunikator mengkonstruksi pesan. Konsep pemaknaan ini tidak terlepas dari perspektif atau nilai-nilai ideologis tertentu serta konsep kultural yang menjadi ranah pemikiran masyarakat di mana simbol tersebut diciptakan. Semiotik mempelajari sistem-sistem, aturan-aturan, konvensi-konvensi yang memungkinkan tandatanda tersebut mempunyai arti (Kriyantono, 
2007:261). Metode semiotika untuk memaknai sastra yaitu dengan menganalisis tanda-tanda pada sastra, dan mencari arti atau makna yang terdapat pada sastra tersebut.

Seseorang menggunakan tanda dalam berkomunikasi untuk mengirim makna tentang objek dan orang lain akan menginterpretasikan tanda tersebut. menurut Saussure, "Signifier dan signified merupakan kesatuan, tak dapat dipisahkan, seperti dua sisi dari sehelai kertas." Tanda (marks) atau bunyi (noises) menghasilkan makna justru karena adanya hubungan dengan tanda-tanda dan cara kerjanya merupakan wilayah kajian semiotika di mana ada dua unsur penting yang menyusun sebuah tanda, yaitu penanda atau yang menandai dan petanda atau yang ditandai. Penanda adalah bentuk formal tanda itu, dalam bahasa berupa satuan bunyi atau huruf dalam sastra tulis, sedangkan petanda adalah artinya, yaitu apa yang ditandai oleh penandanya itu.

Sistem penandaan seperti bahasa, dalam teori semiotika, dipahami sebagai "pengaturan dan penataan" tanda-tanda yang membentuk makna dari dalam dirinya sendiri lewat serangkaian perbedaan konseptual dan bebunyian. Tradisi semiotik terdiri atas sekumpulan teori tentang bagaimana tanda-tanda merepresentasikan benda, ide, keadaan, situasi, perasaan dan kondisi di luar tanda-tanda itu sendiri. (Littlejohn, 2009: 53).

Kajian semiotika yang dibahas dalam kesenian nandung ini adalah kajian semiotika, yang membahas tentang sintaksis, semantik, dan pragmatik. Aart Van Zoest (dalam Sudjiman \& Zoest, 1992:5) menyebut semiotika sebagai studi tentang tanda dan segala sesuatu yang berkaitan dengannya seperti cara berfungsinya, hubungannya dengan tanda-tanda lain, pengirimannya, dan penerimaannya oleh mereka yang mempergunakannya (Sahid, 2016:2).

Aart Van Zoest (dalam Rusmana, 2014: 33) mengatakan bahwa berkenaan dengan masalah tanda-tanda dalam bahasa, Charles Morris, membagi tiga klasifikasi semiotika sebagai berikut, (1) Semiotika sintaksis (studi relasi formal tanda-tanda), yaitu studi tentang tanda yang berpusat pada penggolongan, hubungan antar tanda, proses kerja sama dalam menjalankan fungsinya, (2) Semiotik semantik (studi relasi dengan penafsirannya) yaitu studi tentang tanda yang menonjolkan hubungan tanda-tanda dengan acuannya dan interprestasi yang dihasilkannya, (3) Semiotika pragmatik, yaitu studi tanda yang mementingkan hubungan antar tanda dengan pengirim dan penerimanya.

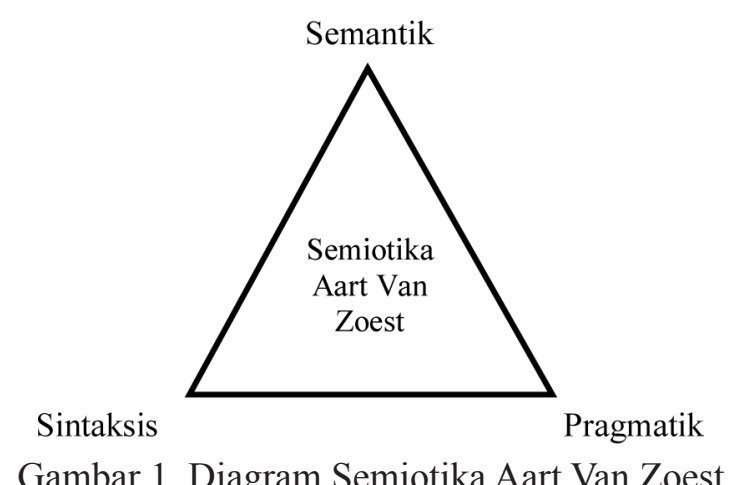

Teks secara keseluruhan merupakan tanda dengan semua cirinya bagi pembaca, teks sastra ini menggantikan sesuatu yang lain yakni, kenyataan yang dipangil yang secara kasar dapat ditunjuk dalam penulisannya, ciri-ciri penyajian dalam teks-teks adalah suatu tanda yang dibangun dari tanda-tanda yang lain yang lebih rendah yang memiliki sifat kebahasaan. (Zoest, 1993:61).

\section{Nandung}

Penyair besar Ahmad Syauqi Bey mengungkapkan bahwa "kekalnya suatu bangsa ialah selama akhlaknya kekal, jika akhlaknya sudah lenyap, musnah pulalah bangsa itu". Ungkapan tersebut, dapat dipahami bahwa akhlak merupakan suatu hal yang sangat penting dalam diri ini untuk memajukan sebuah bangsa. Kepribadian dan perilaku yang baik tentu akan sangat berpengaruh dalam kehidupan sosial, sehingga akan terciptanya ketentraman dan kedamaian dalam kehidupan ini.

Penanaman akhlak yang baik sudah seharusnya diterapkan kepada anak-anak sejak dini. Kesenian nandung di Kota Rengat Kabupaten Indragiri Hulu, mengandung nilai- 
nilai yang berisikan tentang akhlak mulia, petuah agama, dan nasehat telah disampaikan kepada anak-anak sejak dari buaian (sejak kecil). Penanaman nilai Islami sudah terlihat dari awal penuturan syair nandung ini, yaitu dibacakannya kalimat La Ilaha Illallah, Muhammad Rasulullah. Hal ini senantiasa disampaikan untuk selalu mengingat Allah SWT dan Nabi Muhammad SAW.

Istilah nandung (menandung anak = nyanyian untuk menidurkan anak) sebenarnya dikenal secara meluas hampir di seluruh kawasan Kabupaten/Kota dalam wilayah Provinsi Riau, seperti: Kota Dumai dan Pekanbaru, Kabupaten Pelalawan, Siak Sri Indrapura, Bengkalis, Rikan Hilir, Rokan Hulu, Indragiri Hilir, dan Indragiri Hulu. Istilah nandung yang dimaksud dalam hubungannya dengan salah satu genre sastra lisan masyarakat Indragiri Hulu dapat didefinisikan sebagai berikut: rangkaian kata berbentuk pantun yang dinyanyikan dengan irama untuk mendodoi atau menidurkan anak di kalangan masyarakat tempatan dan atau yang berasal dari Indragiri Hulu. (Darmawi, 2006: 17).

Dari terminology tersebut, dapat diuraikan maksud dan maknanya menurut pembagian term, yaitu:

1. Term, rangkaian kata: adalah kumpulan beberapa kata yang terpilih berbentuk kalimat. Satu baris kalimat terdiri atas empat sampai delapan kata.

2. Term, berbentuk pantun: adalah salah satu bentuk sastra klasik Melayu yang terdiri atas 4 (empat) baris dalam satu bait: Dua baris pertama merupakan sampiran dan dua baris terakhir merupakan isi dengan rima akhir: $a . b-a . b$.

3. Term, yang dinyanyikan dengan irama: adalah untaian dan rangkaian nada yang dilagukan dengan irama sejenis syair (irama nandung). Irama antara bait yang satu dengan yang lain sama. Antara bait diselingi dengan kata La Ilaha Illallah... 1 sampai 3 kali.

4. Term, untuk mendodoi atau menidurkan anak: adalah nandung yang didendangkan kaum perempuan untuk menidurkan anak (biasanya) dalam buaian atau gendongan dan pangkuan.

5. Term, di kalangan masyarakat tempatan dan atau berasal dari Indragiri Hulu: adalah masyarakat tempatan (Melayu) yang berada di wilayah atau masyarakat perantau yang berasal dari Kabupaten Indragiri Hulu.

Berdasarkan kesatuan term tersebut dapat ditegaskan bahwa yang dimaksud dengan nandung adalah rangkaian kata berbentuk pantun dan dinyanyikan dengan irama yang khas untuk menidurkan anak di kalangan masyarakat Melayu Indragiri Hulu (Darmawi, 2006:17-18).

Kesenian nandung termasuk jenis sastra lisan. Nandung bisa dikatakan syair jika dilihat dari teksnya, jika dilihat dari penuturannya nandung ini juga bisa dikatakan sebagai nyanyian, karena cara melantunkannya dengan dinyanyikan. Nandung adalah sastra lisan yang lahir dari masyarakat melayu itu sendiri, yang menginginkan anaknya agar menjadi orang yang berguna. Nandung ini berlandaskan asas-asas Islami yang dapat dibuktikan dengan banyaknya syair tentang ajaran-ajaran agama Islam.

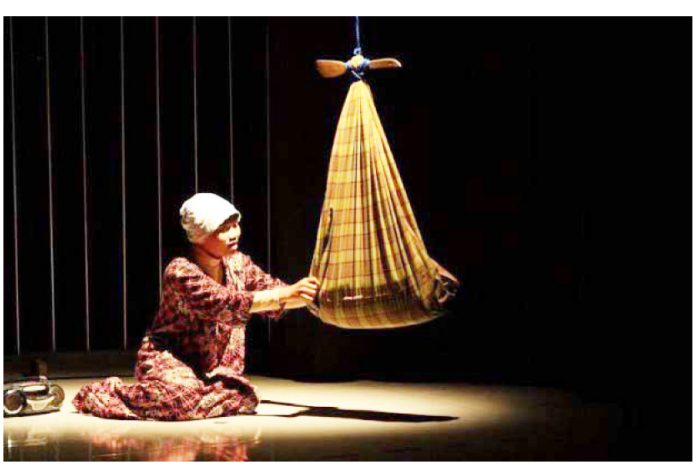

Gambar 2. Ibu sedang menidurkan anaknya di dalam buaian.

(Sumber: www.beritatanjabtim.com)

Anak ditidurkan dalam buaian, kemudian dilantunkan syair nandung dengan menggunakan irama khas melayu Kota Rengat yang mendayudayu. Dari penuturan syair nandung ini, diharapkan anak akan menjadi orang yang memiliki akhlak mulia, selalu ingat kepada agama, selalu menghormati dan menyayangi 
orang tua, serta berperilaku baik dalam menjalani kehidupan. Agar kesenian ini tidak punah dan nilai-nilai luhur tetap dilestarikan, pemerintah Kota Rengat, khususnya bidang budaya dan pariwisata, menjadikan kesenian nandung dalam bentuk festival yang diperlombakan, sehingga keberadaan nandung ini diharapkan akan selalu terjaga.

Nandung di Kabupaten Indragiri Hulu tidak hanya terdapat di sekitaran Kota Rengat, di suku pedalaman Talang Mamak juga terdapat nandung, akan tetapi memiliki konteks yang berbeda dengan nandung yang ada di Kota Rengat. Nandung di Kota Rengat lebih ditujukan kepada anak, sedangkan nandung di suku Talang Mamak memiliki konteks yang lebih luas, seperti untuk mengingatkan anak perempuannya ketika sedang bersama lawan jenisnya, untuk suami yang sedang berburu di hutan atau pergi ke ladang, untuk tradisi pengobatan, dan pujipujian pada hari peringatan hari besar mereka. (Wawancara Mailiswin, 23 Februari 2017).

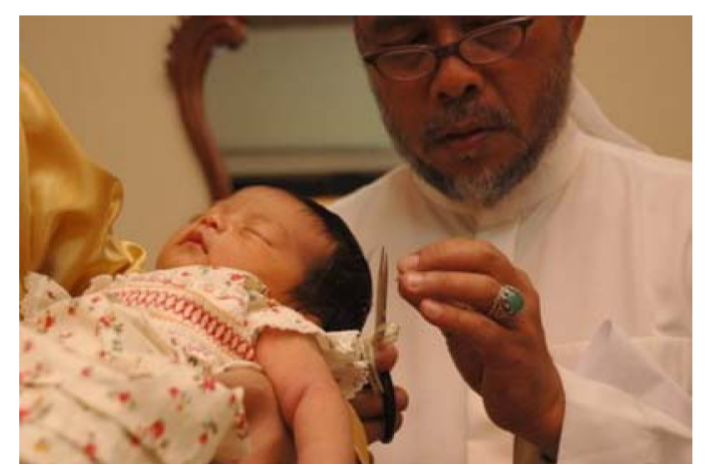

Gambar 3. Kesenian nandung juga dilantunkan saat mencukur rambut dan memberi nama anak. (Sumber: www.fimadani.com)

Nandung di Kota Rengat muncul dari spontanitas ibu-ibu pada zaman dahulu, karena tidak adanya sarana hiburan yang lain. Para ibu pun kemudian bernandung untuk menghibur diri sambil menidurkan anaknya, sekaligus memberikan penanaman nilai-nilai budi pekerti yang luhur dalam syair yang mereka nandungkan. Syair nandung yang ada di sekitaran Kota Rengat, tidak ada yang baku, karena syair nandung ini terbentuk dari spontanitas ibu- ibu yang menandungkannya, tergantung dari kemahiran masing-masing, akan tetapi tetap berisikan tentang petuah agama, akhlak mulia, dan nasehat. Sebenarnya nandung tidak hanya dilantunkan oleh ibu-ibu, bapak-bapak serta kakek dan nenek si bayi pun bisa melantunkan nandung khususnya pada saat tradisi mencukur rambut dan memberi nama anak.

\section{Makna Nandung Dalam Teori Semiotika}

Nandung dilantunkan untuk memberi petuah, nasehat, ajaran agama, dan akhlak kepada anak-anak. Syair nandung mengandung makna-makna yang berbeda pada setiap bagiannya. Aart Van Zoest (dalam Sudjiman \& Zoest, 1992:5) menyebut semiotika sebagai studi tentang tanda dan segala sesuatu yang berkaitan dengannya seperti cara berfungsinya, hubungannya dengan tanda-tanda lain, pengirimannya, dan penerimaannya oleh mereka yang mempergunakannya (Sahid, 2016:2). Untuk mengetahui makna yang terdapat di dalam nandung, maka digunakan teori semiotika yang membahas tentang sintaksis, semantik, dan pragmatik. Berikut penjelasan dari sebagian syair nandung yang terdapat dalam buku Sastra Lisan Nandung Indragiri Hulu dari sintaksis, semantik, dan pragmatik.

\section{Sintaksis}

Sintaksis berasal dari bahasa Belanda yaitu syntaxis. Terdapat beberapa pendapat para ahli tentang sintaksis: (1). Sintaksis adalah telaah mengenai pola-pola yang dipergunakan sebagai sarana untuk menggabung-gabungkan kata menjadi kalimat. (2). Sintaksis merupakan analisis mengenai konstruksi-konstruksi yang hanya mengikutsertakan bentuk-bentuk bebas. (3). Sintaksis merupakan bagian dari tata bahasa yang membicarakan struktur frasa dan kalimat. Sintaksis membahas tentang selukbeluk wacana, kalimat, atau teksnya. Berikut sepenggal teks dari syair nandung.

\section{La Ilaha Illallah \\ Muhammad Rasulullah}

Pualam diasah licinnya meningkat

Susun bertembung-nak syang-uratnya merah 
Dengan Bismillah membuka kalimat

Semoga nandung-nak sayang-membawa berkah

Rebung bambu iris iriskan

Perahlah santan-nak sayang-tanak berkuah

Dudu si dudu bunda nandungkan

Dengarlah intan-nak sayang-nandung petuah

Indah nian bunga di taman

Teman dilingkung-nak sayang-kawat berduri

Selama ananda dalam kandungan

Sakit dan perih-nak sayang-bunda alami

Datuk Panglima menghadap baginda Mengharap titah-nak sayang-Raja berperi

Bunda bahagia mengandung ananda

Sebagai anugrah-nak sayang-Ilahi Rabbi

\section{La Ilaha Illallah}

Muhammad Rasulullah

Alif mulakan huruf Hijaiyah

Hingga ke Ya-nak sayang-genaplah sebutan

Bermula iman karena aqidah

Allah ta'ala-nak sayang-engkau tauhidkan

Buluh dibelah tegak berdiri

Potong seruas-nak sayang-raut rautkan

Takdirnya Allah suratan diri

Tertulis jelas-nak sayang-digaris tangan

Jika menjura tabik bersalam

Sayanglah Datin-nak sayang-kepada jelata

Jika sempurna iman dan islam

Jadilah muhsin-nak sayang-berakhlak mulia

Sempurna helat karena beradat

Terpelihara harkat-nak syang-terpelihara marwah

Sempurnakan syariat menuju hakikat

Niscaya makrifat-nak sayang-kepada Allah

La Ilaha Illallah

Muhammad Rasulullah

Lagu berlagu pantun bersambung

Rancak irama diikuti tari

Dudu sidudu nandung dinandung

Akhlak yang mulia hiaskan diri
Kesumba lurik warna kebaya

Dipakai dara seri biduan

Berbuat baik pada orang tua

Akhlak utama setiap insan

Kalau terbujur lintangkan saja Kayu yang bulat belah di tengah

Kalau terlanjur berbuat dosa

Bersegera taubat kepada Allah

Tepian perigi tangga bertakik

Licinnya pasti mengancam jiwa

Jangan sekali bersifat munafik

Rasul benci Allah pun murka

Syair nandung di atas, terdiri dari 4 baris per 1 bait, kecuali pada kalimat penyambungnya yaitu pada kalimat La Ilaha Illallah, Muhammad Rasulullah. Tiap tiap bagian disampaikan dengan lantunan yang sama. Pembacaan lirik nandung ini, dilafalkan dengan dialek bahasa melayu Kota Rengat, yang pada umumnya huruf "a" pada akhir kalimat, berubah menjadi "e".

Bahasa yang digunakan dalam penuturan syair nandung ini, seperti bahasa Indonesia pada umumnya, mudah dimengerti dan dipahami, hanya saja dialek yang digunakan adalah dialek khas masyarakat melayu di Kota Rengat dan sekitarnya, seperti Kampung Pulau, Kampung Besar Seberang, dan Rantau Mapesai.

Lirik nandung seperti lirik dalam pantun, terdapat bagian sampiran dan isi, contohnya pada lirik bagian pertama Pualam diasah licinnya meningkat Susun bertembung-nak sayang-uratnya merah, kalimat ini merupakan kalimat sampiran, yang akan disambung oleh kalimat isi seperti Dengan Bismillah membuka kalimat Semoga nandung-nak sayang-membawa berkah. Pola yang terdapat adalah pola a $\mathrm{b}$ dan a b, seperti:

- Pola A

Pualam diasah licinnya meningkat

- Pola B

Susun bertembung-nak sayang-uratnya merah

- Pola A

Dengan Bismillah membuka kalimat 
- Pola B

Semoga nandung-nak sayang-membawa berkah

Syair yang dituliskan di atas, merupakan penggalan dari syair nandung yang terdapat dalam buku Sastra Lisan Nandung Indragiri Hulu, sedangkan dalam kehidupan seharihari, lirik yang disampaikan bisa saja berbeda, tergantung dari si penutur (ibu) yang akan menidurkan anaknya. Lirik syair nandung yang tidak baku ini, dikarenakan tiap-tiap ibu memiliki kemahiran yang berbeda untuk merangkai kata, panjang pendek lantunannya, serta isi yang ingin disampaikannya. Akan tetapi, dalam syair nandung ini, tidak akan terlepas dari lirik yang berisikan tentang agama, akhlak, kasih sayang orang tua, dan nasehat.

Pembacaan syair nandung ini, tidak harus disampaikan dalam durasi yang lama, contohnya dari syair nandung di atas, jika si anak (bayi) telah tertidur, bisa saja ibunya berhenti melantunkan nandung pada kalimat La Ilaha Illallah, Muhammad Rasulullah bagian ketiga, hal ini terjadi karena si ibu akan melanjutkan kegiatannya di rumah, seperti melanjutkan kegiatan memasak, mencuci piring, dan membersihkan rumah.

\section{Semantik}

Dari paparan sintaksis yang dijelaskan, maka semantik atau arti kata/bahasa yang terdapat dari tiap bagian bisa dijelaskan sebagai berikut!

\section{La Ilaha Illallah \\ Muhammad Rasulullah}

(Selalu mengingat Allah SWT dan Nabi Muhammad SAW)

Pualam diasah licinnya meningkat Susun bertembung-nak sayang-uratnya merah Dengan Bismillah membuka kalimat

Semoga nandung-nak sayang-membawa berkah

(Sebelum nandung dilantunkan untuk menidurkan anak, harus dimulai dengan Bismillah)
Rebung bambu iris iriskan

Perahlah santan-nak sayang-tanak berkuah

Dudu si dudu bunda nandungkan

Dengarlah intan-nak sayang-nandung petuah

(Ibu menginginkan anaknya mendengarkan

nandung yang akan disampaikan, yaitu tentang petuah-petuah)

\section{Indah nian bunga di taman}

Teman dilingkung-nak sayang-kawat berduri

Selama ananda dalam kandungan

Sakit dan perih-nak sayang-bunda alami

(Perjuangan ibu selama mengandung anaknya)

Datuk Panglima menghadap baginda Mengharap titah-nak sayang-Raja berperi

Bunda bahagia mengandung ananda Sebagai anugrah-nak sayang-Ilahi Rabbi (Ibu selalu bersyukur karena diberi amanah oleh Allah SWT untuk mengandung si buah hati)

\section{La Ilaha Illallah}

Muhammad Rasulullah

(Selalu mengingat Allah SWT dan Nabi

Muhammad SAW)

Alif mulakan huruf Hijaiyah

Hingga ke Ya-nak sayang-genaplah sebutan

Bermula iman karena aqidah

Allah ta'ala-nak sayang-engkau tauhidkan

(Ibu mengajarkan tentang beriman kepada Allah SWT)

Buluh dibelah tegak berdiri

Potong seruas-nak sayang-raut rautkan

Takdirnya Allah suratan diri

Tertulis jelas-nak sayang-digaris tangan

(Segala sesuatu dalam kehidupan, telah

ditentukan oleh Allah SWT di garis tangan masing-masing)

Jika menjura tabik bersalam

Sayanglah Datin-nak sayang-kepada jelata Jika sempurna iman dan islam

Jadilah muhsin-nak sayang-berakhlak mulia (Sempurnakan iman dan islam, agar menjadi orang yang berakhlak mulia) 
Sempurna helat karena beradat Terpelihara harkat-nak syang-terpelihara marwah

Sempurnakan syariat menuju hakikat Niscaya makrifat-nak sayang-kepada Allah

(Sempurnakan hukum dan aturan islam untuk mencapai keimanan sejati, maka ilmu pengetahuan dan pengalaman yang baik akan datang karena Allah SWT)

\section{La Ilaha Illallah \\ Muhammad Rasulullah}

(Selalu mengingat Allah SWT dan Nabi Muhammad SAW)

Lagu berlagu pantun bersambung Rancak irama diikuti tari Dudu sidudu nandung dinandung Akhlak yang mulia hiaskan diri

(Akhlak yang baik, akan menjadikan diri lebih baik)

Kesumba lurik warna kebaya Dipakai dara seri biduan

Berbuat baik pada orang tua Akhlak utama setiap insan

(Hormati dan patuhi orang tua, karena itu kewajiban yang harus kita lakukan)

Kalau terbujur lintangkan saja Kayu yang bulat belah di tengah Kalau terlanjur berbuat dosa

Bersegera taubat kepada Allah

(Jika melakukan kesalahan, segera minta ampun kepada Allah SWT)

Tepian perigi tangga bertakik

Licinnya pasti mengancam jiwa Jangan sekali bersifat munafik Rasul benci Allah pun murka

(Dalam kehidupan, hindari sifat munafik, karena itu merupakan sifat yang dibenci oleh Allah SWT dan Rasul-Nya)

Dari berbagai macam arti yang terdapat pada bagian-bagian syair nandung ini, bisa dikatakan bahwa nandung ini mengandung ajaran yang sangat baik yang sudah ditanamkan ke anak-anak sejak bayi, yang diharapkan akan diterapkan dalam kehidupan mulai dari buaian, hingga ke liang kubur.

Masyarakat melayu sangat mengutamakan unsur-unsur pendidikan Islami dalam syair nandung ini, setiap kalimat yang disampaikan mengandung arti yang sesuai dengan ajaran agama Islam, seperti beriman kepada Allah SWT dan Rasul-Nya, percaya kepada takdir, menjauhi sifat-sifat yang buruk, menghormati orang tua, serta melakukan kebaikan.

\section{Pragmatik}

Pragmatik menjelaskan tentang kegunaan tanda oleh yang menerapkannya, dan efek bagi yang menafsirkan. Makna dapat dipahami dari penafsiran kata-kata yang disampaikan oleh penutur kepada pendengar, sehingga menghasilkan makna yang sesuai dengan apa yang ingin disampaikan. Teks dan arti dari teks tersebut, memiliki makna yang berbeda pada tiap-tiap bagiannya.

Syair nandung berupa teks yang berisikan tentang petuah, ajaran agama, akhlak dan pendidikan. Ibu menyampaikan syair nandung dengan cara melantunkan dengan irama khas masyarakat melayu Kota Rengat kepada anaknya yang sedang berada dibuaian. Hal yang diharapkan adalah agar kelak anaknya menjadi orang yang patuh kepada agama, patuh kepada orang tua, serta menjalani kehidupan dengan akhlak yang mulia. Ketika nandung dilantunkan, tidak hanya ditujukan kepada anak yang sedang tidur di dalam buaian, ketika ada orang lain yang mendengar, juga bisa menafsirkan isi dari nandung yang dilantunkan. Gambaran yang terdapat dalam syair nandung ini adalah dalam menjalani kehidupan harus berpegang teguh pada agama, dan melakukan segala perintah Allah SWT dan menjauhi segala laranganNya.

\section{KESIMPULAN}

Berdasarkan pembahasan tentang syair nandung dalam masyarakat Kota Rengat Kabupaten Indragiri Hulu, yang dikaji dari teori semiotika, dapat disimpulkan yaitu konsep pertama tentang sintaksis, yaitu membahas 
tentang teks, terdapat 4 baris kalimat pada 1 bait yang serupa dengan pantun, dilantunkan dengan irama khas melayu Kota Rengat, dengan bait yang tersusun dari sampiran dan isi, dengan berpola $\mathrm{a} b$ dan $\mathrm{a} b$. Pada konsep kedua tentang semantik, yaitu membahas tentang arti kata/bahasa, dapat disimpulkan bahwa syair nandung memiliki arti tentang petuah agama, kasih sayang orang tua, akhlak mulia, dan nasehat. Konsep ketiga yaitu pragmatik, membahas tentang makna yang terdapat dari hubungan antara teks dan arti kata/bahasa, dapat disimpulkan bahwa yang diharapkan dari penyampaian syair nandung ini adalah agar kelak anak-anak menjadi orang yang patuh kepada agama, patuh kepada orang tua, serta menjalani kehidupan dengan akhlak yang mulia. Makna yang terdapat dalam syair nandung ini adalah dalam menjalani kehidupan harus berpegang teguh pada agama, dan melakukan segala perintah Allah SWT dan menjauhi segala larangan-Nya, selalu melakukan kebaikan, dan mengingat jasa-jasa orang tua yang telah mendidik dan membesarkan anaknya.

\section{DAFTAR PUSTAKA}

Darmawi, Ahmad. 2006. Sastra Lisan Nandung Indragiri Hulu. Riau. Penerbit : Lembaga Seni Budaya Melayu.

Firduansyah, Dedy. DKK. 2016. Guritan: Makna Syair dan Proses Perubahan Fungsi Pada Masyarakat Melayu di Besemah Kota Pagaralam. Pascasarjana Pendidikan Seni. Universitas Negeri Semarang.
Kriyantono, Rachmat. 2007. Teknik Praktis Riset Komunikasi. Jakarta. Penerbit: Kencana.

Littlejohn, Stephen W. 2009. Teori Komunikasi Theories of Human Communication edisi 9. Jakarta. Salemba Humanika.

Novendra. 2010. Kesenian Tradisional Masyarakat Melayu Provinsi Riau. Tanjung Pinang, Kepulauan Riau. Penerbit: Kementerian Budaya dan Pariwisata Balai Pelestarian Sejarah dan Nilai Tradisional.

Rusmana, Dadan. 2014. Filsafat Semiotika: Paradigma, Teori, dan Metode Interpretasi Tanda dari Semiotika Struktural Hingga Dekonstruksi Praktis. Bandung. Penerbit: Pustaka Setia.

Saharan, DKK. 2011. Sinopsis Cagar Budaya dan Seni Budaya Daerah Kabupaten Indragiri Hulu. Dinas Pemuda Olahraga Budaya dan Pariwisata Kabupaten Indragiri Hulu. Riau

Sahid, Nur. 2016. Semiotika untuk Teater, Tari, Wayang Purwa, dan Film. Semarang. Penerbit : Gigih Pustaka Mandiri.

Subroto, Edi. 2011. Pengantar Studi Semantik dan Pragmatik (Buku 1. Pengantar Studi Semantik). Surakarta. Penerbit: Cakrawala Media.

Sunarto. 2016. 8 Tokoh Semiotika. Yogyakarta. Penerbit : Panta Rhei Books.

Van Zoest, Art. 1993. Semiotika Tentang Tanda, Cara Kerjanya, dan Apa yang Kita Lakukan Dengannya. Jakarta. Penerbit: Yayasan Sumber Agung Press. 